\title{
SPREKENDE BUIKEN
}

In dit opstel wil ik drie godenbeelden bespreken, die op het eerste gezicht weinig meer met elkaar gemeen hebben, dan dat ze alledrie in de $9^{e}$ eeuw op Java uit dezelfde vulkanische steensoort gehouwen zijn. Ik hoop aan te tonen dat er wel degelijk een overeenkomst bestaat. Laten we eerst naar de verschillen kijken en daarna naar de overeenkomst.

\section{Drie verschillende godenbeelden}

De twee beelden links (afb. 1 en 2) zijn in 1928 samen geschonken door de toenmalige voorzitter van de Vereniging van Vrienden der Aziatische Kunst, de heer H.K. Westendorp. De beelden zijn $76 \mathrm{~cm}$. hoog. Ze vormen een paar van tegendelen, namelijk van fijn en grof. De verfijnde figuur, uiterst links, staat ontspannen voor zich uit te kijken. Hij is gekleed in een heupkleed van dunne stof tot op zijn enkels dat op zijn plaats wordt gehouden door middel van sjerpen met grote strikken op zijn heupen. Verder draagt hij geen kleding, maar wel veel sieraden: banden om de hals, bovenarmen, polsen en enkels, een band dwars, en een kastekoord schuin over het bovenlichaam. Zijn haar is in een hoge knot opgebonden en versierd met een diadeem, banden en spelden. Door zijn rechterhand laat hij een gebedsnoer glijden. Met zijn linkerhand houdt hij de stengel vast van een hoog opschietende lotusplant, waarvan de bloem boven zijn schouders prijkt. Op de bloem ligt een juweel. Achter zijn hoofd een aureool. Aan zijn rechterkant staat een drietand waaraan zowel een rinkelbel als een vliegenwaaier is bevestigd. De drietand, en ook de bel en waaier, zijn typische voorwerpen die behoren tot de hindoegod Shiva. Deze verfijnde figuur maakt dan ook deel uit van Shiva's entourage. Hij is een wachter van een Shiva-heiligdom, wordt Nandishvara genoemd, en staat steeds aan de linkerkant van de toegang.

Aan de rechterkant van de toegang staat steeds de grove figuur. Hij wordt Mahakala genoemd. Deze draagt een heupkleed dat tussen zijn benen omhoog is getrokken en met een eenvoudiger sjerp zonder strikken op zijn plaats wordt gehouden. Verder draagt hij dezelfde sieraden als zijn metgezel, maar van andere vormgeving. Zijn oorsieraden, bijvoorbeeld, zijn grote ronde schijven die de gaten in zijn oorlellen vullen, waar zijn metgezel kleine clipjes draagt, en hij heeft geen band dwars om zijn borst, maar wel weer een kastekoord. Zijn haar is eveneens hoog opgemaakt en versierd, maar het is veel dikker. Hij heeft helemaal veel meer haar: behalve de knot op zijn hoofd, hangen grote, dikke krullen op zijn schouders en zijn bovenlip is bedekt met een forse snor. Zijn mond hangt open en zijn ogen puilen uit van ingehouden woede. Hij lijkt geen voorwerpen bij zich te hebben, maar ergens in zijn bewogen verleden is zijn vaste attribuut verloren gegaan. In zijn linkerhand

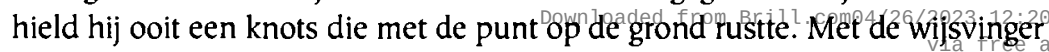


van zijn rechterhand priemt hij vooruit: een dreigend gebaar gericht tegen ongure elementen om uit de buurt te blijven, anders zwaait er wat!

Het derde beeld rechts (afb. 3) is in 1936 aangekocht van de Haagse verzamelaar J.G. Huyser. Het is $100 \mathrm{~cm}$. hoog. Deze figuur staat er rustig bij. Hij draagt, net als Nandishvara, een heupkleed dat tot zijn enkels reikt en dat ook met een sjerp met strikken op zijn heupen en een eenvoudiger sjerp wordt vast gehouden. Daarbovenop ligt nog een rijkversierde ceintuur. Hij draagt bovenarmbanden en polsringen en weer een ander type oorsieraden: een ring aan de onderkant versierd met een bloem, gehaakt door de gaten in zijn oorlellen. Ook hij heeft het haar hoog opgestoken en versierd met diadeem en spelden. Achter zijn hoofd een aureool. Helaas is zijn voorhoofd en diadeem flink beschadigd. Hij heeft zijn snor en sik laten staan. De sik is zelfs zo lang en dun dat hij er twee knopen in heeft kunnen leggen. Schuin over zijn bovenlichaam draagt hij een bandelier. Hij is beslist zwaarlijvig. Door zijn rechterhand draait hij een gebedsnoer en in zijn linkerhand houdt hij een waterkruik. Op zijn linkerschouder ligt een vliegenwaaier. Aan de halsketting hangen links op zijn rug een waterpotje, en rechts een rinkelbel. Aan zijn rechterkant staat tegen de achterplaat een drietand. De drietand en het gebedsnoer wijzen weer op Shiva. Deze figuur is dan ook de Shivaitische leraar Agastya.

In Javaanse tempels gewijd aan Shiva staat Agastya steeds in de zuidelijke nis aan de buitenkant. In de noordelijke nis bevindt zich steeds een beeld van de godin Durga-die-de-Buffeldemon-doodt. De toegang met de wachters Nandishvara en Mahakala is meestal naar het oosten gericht en in de nis aan de achterzijde, meestal dus de westzijde, bevindt zich steeds een beeld van de god met de olifantenkop en het dwergenlichaam, Ganesha. In de tempelkamer staat het beeld van Shiva zelf, meestal in zijn symbolische gestalte van de lingga.

\section{Overeenkomst}

Bij vergelijking van de lichaamshouding van de drie godheden, valt op hoe verschillend ze er bij staan. De verfijnde Nandishvara staat alsof hij het bevel 'op de plaats rust' heeft gekregen: met groot gemak spant hij de nodige spieren en heeft zijn lichaam geheel onder controle. Indien nodig, kan hij onmiddellijk tot actie overgaan. De grove Mahakala, daarentegen, lijkt krampachtig op zijn voeten heen en weer te wippen, en lijkt meer op een uitsmijter van een nachtkroeg die niet kan wachten om iemand een oplawaai te verkopen. Hij kromt zelfs zijn grote tenen. In de gezette Agastya zit geen beweging, in tegenstelling tot de twee wachters. Hij staat juist pal rechtop en straalt een zekere rust en autoriteit uit. Je kunt gerust naar hem toe gaan, en hij zal je vriendelijk te woord staan.

Wanneer we ons nu concentreren op de buiken van de drie godheden, dan blijken die ons nog meer over hun karakter te vertellen. De buik van Nandishvara is onopvallend, fraai en plat als van een atleet, veroorzaakt door matigheid en voldoende lichaamsbeweging. Het karakteriseert hem als iemand die weloverwogen en beheerst te werk gaat. De buik van Mahakala is papperig en slap door onmatig en ongezond eten. Hij is opvliegend en heeft zijn behoeften niet onder controle. De zwablijifigheid ban Agastya is $^{2023}$ 12:20:41PM 

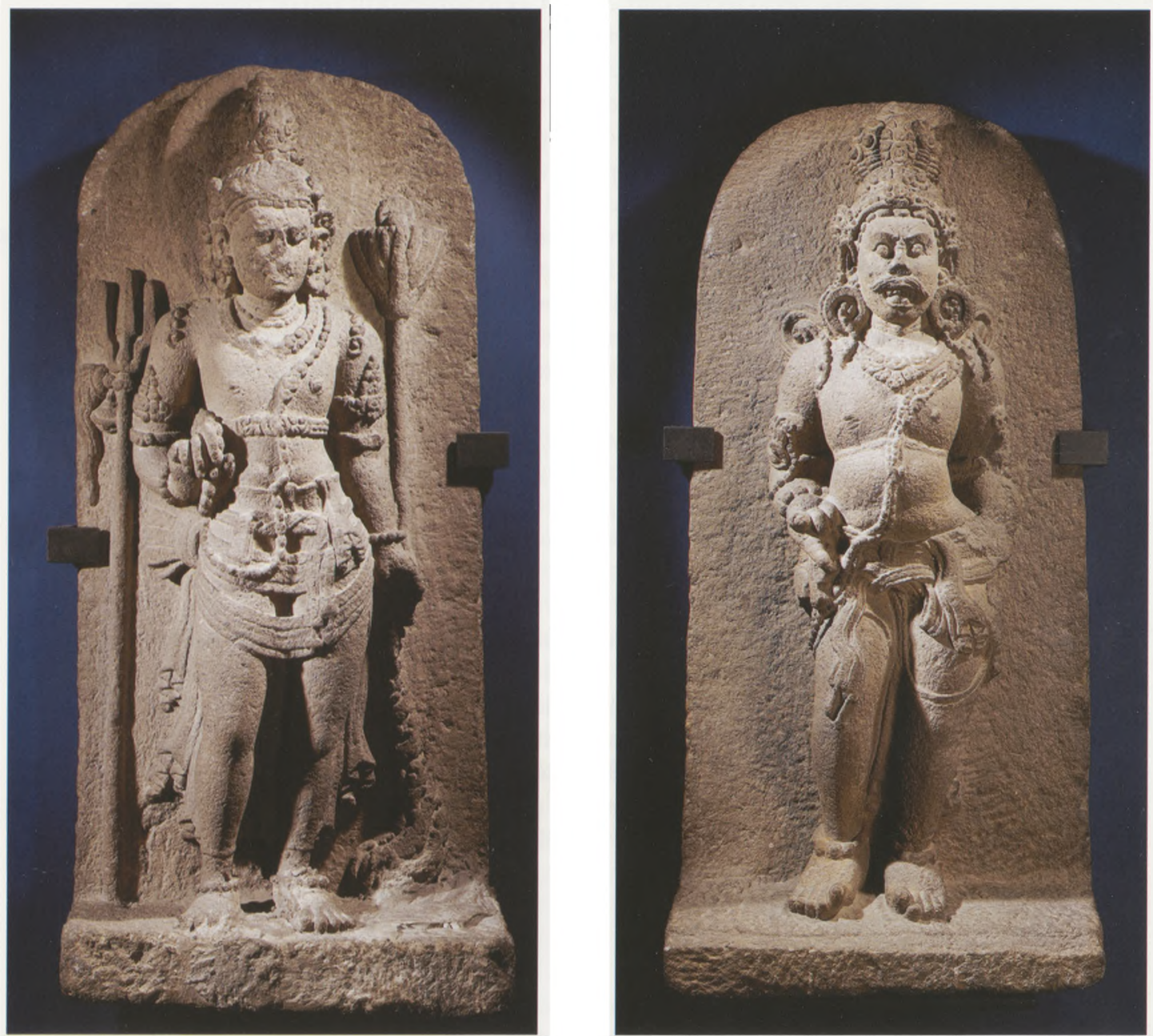

Afbeelding 1

Nandishvara, andesiet

h. $75,0 \mathrm{~cm}$.

Indonesië, Midden-Java,

Prambanan-vlakte,

9 eeuw

Rijksmuseum, geschenk

H.K. Westendorp,

inv.nr. AK-MAK-232a
Afbeelding 2

Mahakala, andesiet

h. $75,0 \mathrm{~cm}$.

Indonesië, Midden-Java,

Prambanan-vlakte,

$9^{e}$ eeuw

Rijksmuseum, geschenk

H.K. Westendorp,

inv.nr. AK-MAK-232b
Afbeelding 3 (pag. 45)

Agastya, andesiet

h. $100,0 \mathrm{~cm}$.

Indonesiè, Midden-Java,

Kedu-vlakte, $9^{e}$ eeuw

Rijksmuseum, inv.nr.

AK-MAK-238

Downloaded from Brill.com@4/26/2023 12:20:41PM 

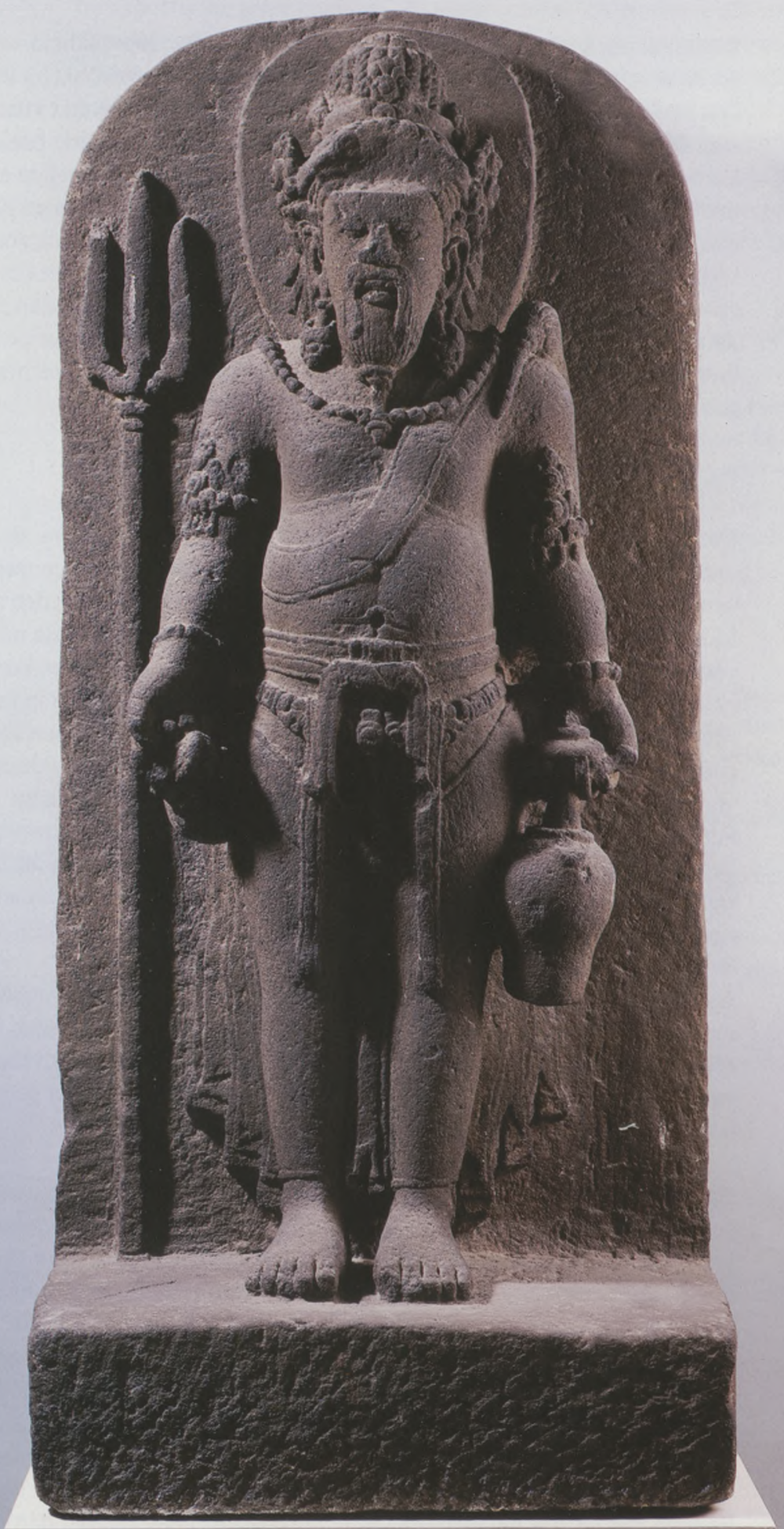
ontstaan door het bereiken van een rijpe leeftijd. Het is de embonpoint van de ouderdom die gepaard gaat met ervaring en wijsheid. Hij is een bezadigde leraar met geestelijk overwicht.

Zelden of nooit wordt in de oude Javaanse kunst de persoonlijkheid van een godheid zo subtiel in de details van het lichaam weergegeven, als bij deze drie beelden. Ze zouden best door dezelfde beeldhouwer gemaakt kunnen zijn. Hierin zit nu de voornaamste overeenkomst tussen deze drie beelden. Verder zijn de achterplaten met de afgeronde bovenhoeken hetzelfde en is de driehoekige versiering van de bovenarmbanden van Nandishvara en Agastya hetzelfde. De wachterbeelden zijn iets kleiner dan dat van Agastya, zoals dat bij beelden van één tempel gebruikelijk is. De drie beelden zouden best van een en dezelfde tempel afkomstig kunnen zijn. Mocht dit zo zijn, dan maakt dit nieuwsgierig naar de buiken van de bijbehorende beelden, naar de toch al fabelachtige buik van Ganesha, maar ook naar die van de zeer krachtige godin van Durga-die-de-Buffeldemon-doodt.

\section{Commentaar}

Deze beelden zijn eerder voortreffelijk besproken door Th. van Erp, de restaurator van de Borobudur in 1911, en enige tijd vervangend conservator van de collectie van de Vereniging. ${ }^{1} \mathrm{Hij}$ legt daarin allerlei verbanden met India, iets wat wij tegenwoordig niet zo vaak zouden doen. Zelfs de namen voor deze drie godheden die tegenwoordig geheel ingeburgerd zijn, komen pas laat voor in een Javaanse context: Nandishvara en Mahakala in het twaalfde-eeuwse Oud-Javaanse gedicht Smaradahana ${ }^{2}$ en de constellatie van godenbeelden in een Shiva-tempel, die door de gehele Klassieke Periode te vinden is, wordt pas genoemd in de zestiende-eeuwse tekst, de Tantu Panggelaran, maar daar worden de wachters Kala en Anukala genoemd. ${ }^{3}$ Tegenwoordig gaan we er van uit dat alleen die cultuurelementen uit India werden overgenomen die overeenkomst hadden met al op Java bestaande equivalenten.

Als mogelijke herkomst van de beelden noemt Van Erp voor de wachters de Prambanan-vlakte en voor de Agastya Tegalrejo, ca $6 \mathrm{~km}$. ten Oosten van Magelang, in de Kedu-vlakte. De gegevens van de eerste zijn zeer vaag en van de tweede zeer twijfelachtig, zodat het me beter lijkt zolang er geen bevestiging voor is, er niet al te zwaar aan te tillen.

Godheden uit het hindoeïsme en boeddhisme worden als mensen voorgesteld. In het algemeen zijn ze jong-volwassenen, maar ze kunnen ook jongeling zijn, en een en dezelfde godheid kan in verschillende van zijn manifestaties volwassen en jong zijn, zoals bijvoorbeeld de bodhisattva Manjushri, of de rijkdomsgod Kubera. Ze kunnen ook oud zijn, zoals Agastya. Er is een heel scala aan mogelijkheden om niet alleen hun geslacht en leeftijd, maar ook karaktereigenschappen tot uitdrukking brengen. Dit kan door lichaamsvorm, stand van het lichaam, kleding, haardracht, sieraden en attributen. Voor het uitbeelden is de lichaamsvorm het subtielst en dat vraagt dus het meest van de kunstenaar, terwijl de attributen eenvoudiger uit te beelden zijn en ook het eenvoudigst te herkennen. Vaak zijn het dan ook uitsluitend de attributen die aangeven om welke godheid het gaat. 
Bij ons drietal is aandacht besteed aan al die mogelijkheden. Er zijn bijvoorbeeld meer attributen dan strikt noodzakelijk. De rinkelbel op Agastya's rug legt, net als de bel aan de drietand van Nandishvara, nog eens de nadruk op hun ascetische levenswandel. De dragers ervan leiden een leven volgens bepaalde onmaatschappelijke regels, maar voor hun levensonderhoud zijn zij juist weer afhankelijk van de maatschappij, namelijk van de aalmoezen van gewone mensen. Daarom kondigen ze hun komst aan door middel van een rinkelbel, zodat men voedsel voor hen klaar kan zetten. Het geven van aalmoezen is, zowel in het hindoeïsme als in het boeddhisme, een goede daad, waarmee je bijvoorbeeld je kans op opname in de hemel vergroot. De rinkelbellen zijn ook in werkelijkheid teruggevonden. De rinkelaars van hindoeïstische en boeddhistische bedelaars zijn verschillend. ${ }^{4}$

De grove trekken van Mahakala zijn hier nadrukkelijker aanwezig dan bij andere beelden en Nandishvara en Mahakala vormen hier een perfect tegengesteld paar. De grove kenmerken, zoals veel en weelderig haar, open mond en uitpuilende ogen, zijn die van demonen. Ze zijn bijvoorbeeld ook te vinden bij de demon die door Durga gedood wordt en bij de paren wachters van een tempelterrein. Het idee is waarschijnlijk dat Shiva die tegenstelling overstijgt. Het sterke van onze drie beeldhouwwerken is dat de godheden herkenbaar zijn aan hun buiken alleen.

\section{Noten}

1. Th.Van Erp, 'Twee Poortwachters van een Çiwa-heiligdom uit de Prambanan-vlakte' Maandblad voor Beeldende Kunsten, 1926, pp. 144-149 en 'Een fraai HindoeJavaansch beeld van Çiwa als goddelijke leeraar' Maandblad voor Beeldende Kunsten, 1937, pp. 204-212.

2. R.Ng. Poerbatjaraka, Smaradahana. Oud-Javaansche tekst en vertaling, Bandoeng 1931, verzen V, 13 en VI, 7, 10, 11.

3. Th.G.Th. Pigeaud, De Tantu Panggelaran. Een Oud-Javaansch Prozagedicht, Den Haag, 1924, pp. 96-97 en 1164-165.

4. P.C.M. Lunsingh Scheurleer en M.J. Klokke, Divine Bronze. Ancient Indonesian Bronzes from AD 600 to 1600, Amsterdam en Leiden 1988, nrs. 74 en 103. 


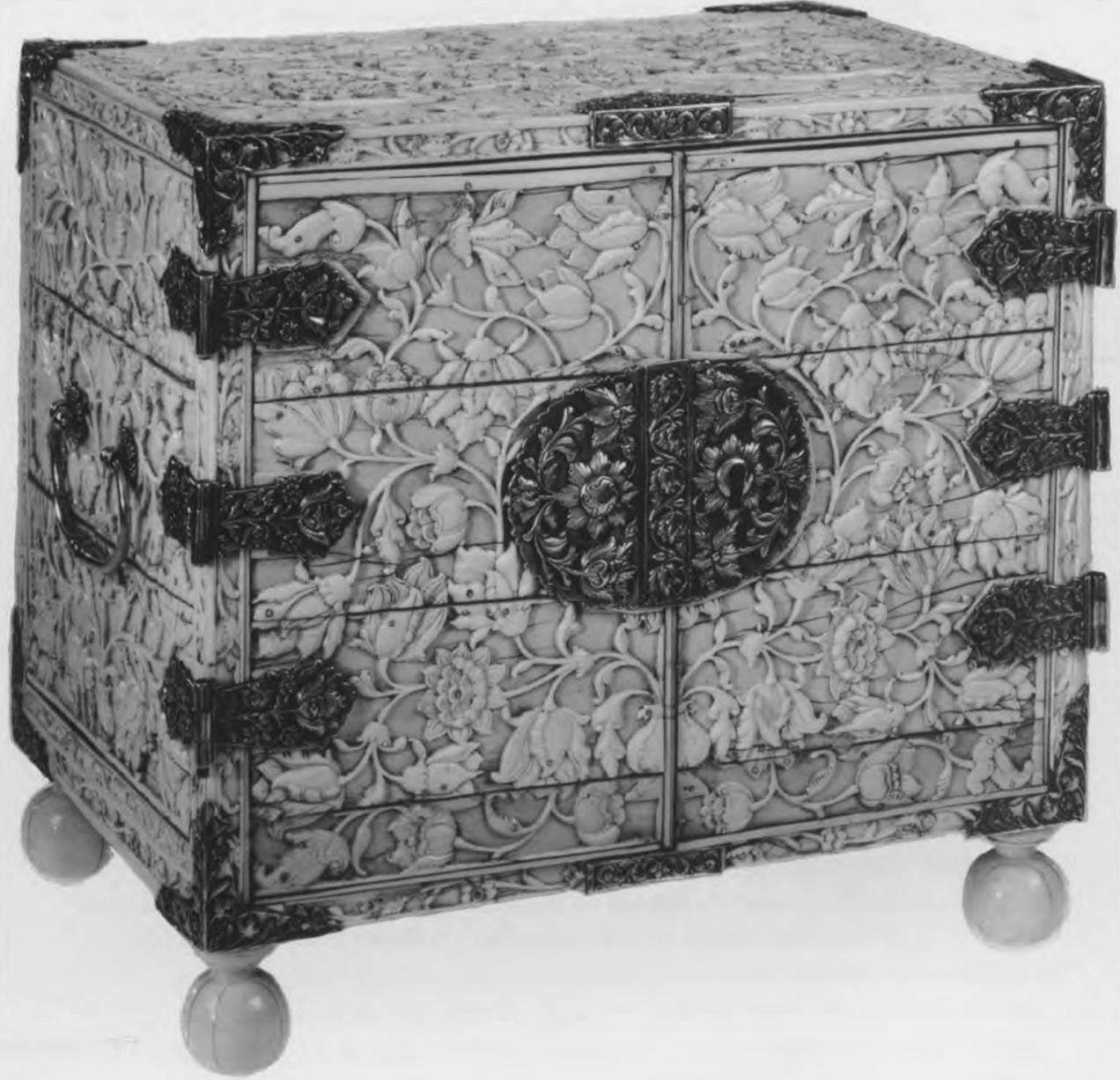

Afbeelding 1

Kastje, hout bekleed

met ivoor en voorzien

van zilverbeslag, de

deuren gesloten

h. $29,5 \mathrm{~cm}$., b. $32,5 \mathrm{~cm}$.,

d. $22,5 \mathrm{~cm}$.

Sri Lanka (toeschrij-

ving), ca. 1700

Rijksmuseum, inv.nr. 